\title{
One's learning is never complete: chronic high-pressure life-treating pleural effusion in post-pneumonectomy patients
}

\author{
Giorgio Lo Iacono ${ }^{1}$, Francesco Petrella ${ }^{1,2}$, Monica Casiraghi ${ }^{1}$, Lorenzo Spaggiari ${ }^{1,2}$ \\ ${ }^{1}$ Department of Thoracic Surgery, IEO, European Institute of Oncology IRCCS, Milan, Italy; ${ }^{2}$ Department of Oncology and Hemato-Oncology, \\ Università degli Studi di Milano, Milan, Italy \\ Correspondence to: Giorgio Lo Iacono, MD. Via Giuseppe Ripamonti, 435 - 20141 Milano, Italy. Email: giorgio.loiacono@ieo.it.
}

\begin{abstract}
Post-pneumonectomy syndromes are a series of rare postoperative complications observed as potential consequence after pneumonectomy. In its most frequent presentation, it is usually caused by mediastinal structures rotation and displacement towards the operated side, resulting in organs compression. We describe a case of reverse mediastinal shift, occurred 25 years after an emergency left pneumonectomy due to a motorcycle accident. Unlike what usually happens, the cavity left empty after the operation did not reduce considerably, but we observed an abnormal pleural effusion accumulation up to the displacement of distal trachea and compression of the residual pulmonary artery until its almost complete occlusion. To avoid this potentially deadly complication we placed a pleural drainage in order to prevent cardiopulmonary arrest and reduce symptoms. The "reverse post-pneumonectomy syndrome" can be counted in the spectrum of post-pneumonectomy syndromes and it should be considered in patients with a history of pneumonectomy, which develop dyspnoea, cough or asthenia long after pneumonectomy.
\end{abstract}

Keywords: Post-pneumonectomy syndrome; lung cancer; post-pneumonectomy-like syndrome; pneumonectomy; pleural effusion; case report

Received: 26 December 2019; Accepted: 23 March 2020; Published: 10 October 2020.

doi: $10.21037 /$ shc.2020.04.03

View this article at: http://dx.doi.org/10.21037/shc.2020.04.03

\section{Introduction}

The first pneumonectomy dates 1933, but despite this, the problems linked to this important intervention are always a current clinical practice. Due to the limited survival of patients undergoing pneumonectomy, which is usually performed in patients with locally advanced diseases, long-term observations on these patients are limited. Only a few patients can be evaluated above all for those who have undergone a pneumonectomy due to benign pathology, which in our day appears to be a very limited occurrence, reserved in those cases of advanced infectious pathology (especially in developing countries), or linked to the traumatic pathology (eventuality however equally rare) [Deslauriers 2011]. The profound changes that take place in the body after pneumonectomy allow to adapt the physical needs to the presence of only one lung. One of the manifestations that is already evident early, but that has effects especially in the long-term is hyperinflation, whose origin is still debated between a real emphysema with rupture of alveolar septs and destruction of the lung as a result of stretching and fragmentation of the walls, or simply represents an enlargement of the lung. The hyperinflation of the residual lung can be the basis of one of the known, although rare, complications after surgery: the post-pneumonectomy syndrome. Post-pneumonectomy syndrome is a rare condition arising after pneumonectomy in adults or children. It is due to extreme shift of the mediastinum and heart with the great vessels towards the empty hemithorax $(1,2)$, the result is that major airways together with residual pulmonary artery are compressed against the spine or aorta, resulting in a symptomatic central airway compression and pulmonary hypertension (3). Similar aetiology has the post-pneumonectomy-like syndromes which emerged when one of the lungs is destroyed due to therapy complications or serious infectious 

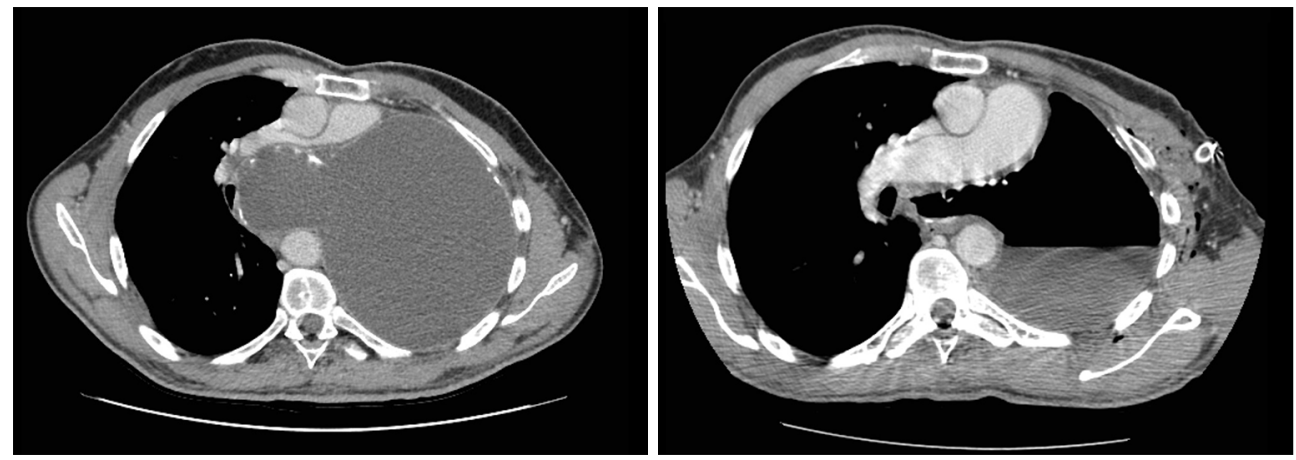

Figure 1 CT scan before (left) and after (right) chest drain. Evidence of the protrusion of mediastinal pleura against trachea and compression of the residual pulmonary artery.

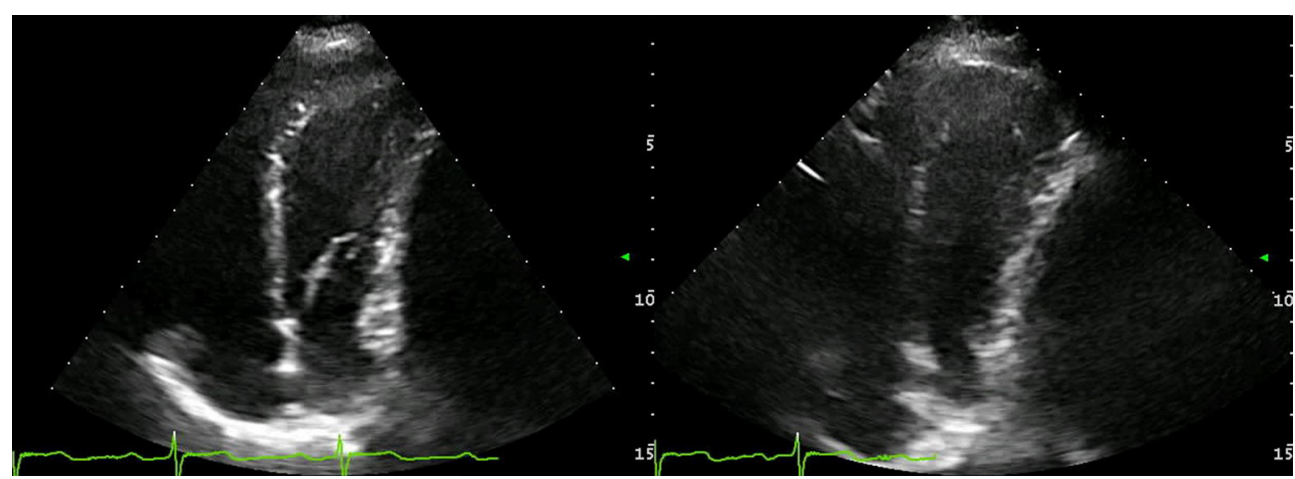

Figure 2 Ultrasound 4-chamber view with compression of the left ventricle.

disease, mimicking post-pneumonectomy syndrome consequences (4).

Thanks to the very long follow-up we report a case of "reverse mediastinal shift", occurring 25 years after left pneumonectomy for motorcycle accident trauma. The patient discloses mediastinal shift toward the residual lung due to anomalous pleural effusion accumulation, displacing trachea and causing compression on the residual pulmonary artery. We present the following article in accordance with the CARE reporting checklist (available at http://dx.doi. org/10.21037/shc.2020.04.03).

\section{Case presentation}

A 15-year-old healthy male patient, with unremarkable medical history, due to motorcycle accident underwent exploratory laparotomy and emergency left pneumonectomy with no sign of damage to the liver o abdomen. Five months later, he developed a bronchopleural fistula treated with partial success by Abruzzini surgical procedure (5). It consists in a trans-sternal approach with wide mediastinal dissection, far from any infected site, in order to close the bronchial stump after bronchopleural fistula's identification. The subsequent management was conservative with local applications of neomycin sulphate until fistula's complete closure.

After 25 years of complete wellness, at 44-year-old, he experienced cough, asthenia and progressive intense dyspnoea. Clinical examination revealed hypoxemia, reduction of breath sounds in the right hemithorax and wheezing. Chest $\mathrm{X}$-ray was unremarkable, while a computed tomography (CT) scan revealed mediastinal shift toward the right residual lung, showing a protrusion of mediastinal pleura causing an almost complete compression of the residual pulmonary artery (Figure 1). Moreover, the CT-scan evidenced an inhomogeneous pleural effusion and presence of diffuse pleural thickenings with calcified plaques.

Cardiac ultrasound showed a slight compression of the left ventricle (Figure 2) due to compression, without 
pulmonary artery hypertension or hemodynamic impairment.

A chest drain was placed with emission of 1,3 liters of jelly brownish liquid. After the procedure, the patient reported immediate relief from the symptoms. Cytological examination was negative for cancerous cells and microbiological culture examinations. Instead, the exudative liquid was described as amorphous materials with red blood lysed cells, histiocytes with hemosiderin pigment, some granulocytes and lymphocytes.

Pleural cavity was then explored by video-assisted thoracoscopy. No macroscopic alterations were found. Pleural biopsy disclosed chronic pleuritic (i.e., pleura's inflammation and thickening), probably due to lung removal, without any sign of neoplasm or infection.

During several years of follow-up, even after antiinflammatory and steroid therapy, hypertensive pleural effusion recurrence is observed annually. Thus, the patient (actual age 55-year-old) performed CT scan and evaluation about once a year to understand whether pleural drainage is needed to avoid hyperdistention and mediastinal shift, or if symptoms rise.

\section{Discussion}

After pneumonectomy, mediastinum shifts toward the empty hemithorax is commonly observed. In a small group of patients, an excessive mediastinal rotation displaces trachea, main bronchus and residual pulmonary artery towards vertebral column or descending aorta. This alteration results in a symptomatic central airway compression and pulmonary hypertension, the so-called post-pneumonectomy syndrome $(6,7)$.

The etiology of this condition has not yet been found, but it seems to be related to the softness and elasticity of mediastinal tissues. This could also explain why these syndromes are usually developed in young patients and children, or in the early postoperative period. Moreover, the observed event infrequency can also be correlated to the unusual long survival, due to pneumonectomy nononcological origins, which does not allow to compare it with other reports. In our case, we had the opportunity to start the follow-up of a 25-year post-pneumonectomy patient, disclosing a hypertensive pleural effusion of the operated side. We have explored all the common causes of pleural effusions: increase in hydrostatic pressure, reduction of oncotic pressure, movements transdiaphragmatic of ascitic fluid, hepatobiliary fistula, intrathoracic malignant neoplasia, infection of the pleural cavity. All the exams were negative, but the result was a growing force in the fluid overcoming the resistance of residual lung, up to the bulging of the mediastinal pleura (Figure 1). The failure of pleura contention resulted in a compression of the residual pulmonary artery and dislocation of the trachea, making emergency chest drainage the only effective treatment for a potential life-threatening condition. The increased pressure in the pleural cavity tries to find a way through the mediastinal pleura, between the heart, anteriorly, and the aorta posteriorly, finding in the mediastinum a "locus minoris resistentiae". Our best supposition on pathological event's genesis is linked to a possible excessive dissection of the posterior mediastinum, during Abruzzini procedure in the adolescence. Although no certain pathophysiological explanation has been found, what is certain is that pleural drainage performed annually is necessary to prevent the onset of symptoms and potential cardiopulmonary arrest. Thus, the best option for the patient is to perform scheduled controls to avoid any major damage. After 38-year from the incident, excluding the pleura effusion recurrence, the patient is healthy and conducting a normal life.

In conclusion, what we could call "reverse postpneumonectomy syndrome" must be considered within the spectrum of post-pneumonectomy syndromes, in patients developing dyspnea, cough or asthenia long after pneumonectomy. The changes related to pneumonectomy are deep in human body and certainly can affect everyday life of the patient who suffers it. The few data available on patients with long survivals do not allow to have a clear picture on the whole spectrum of pathologies that these patients can face. Probably in the future, thanks to the improvement of adjuvant medical therapies, we will find many more patients with long survivals after pneumonectomy for cancer that will allow us to have much more data to analyse in order to better stratify these findings and be able to find more satisfactory explanations.

\section{Acknowledgments}

Funding: This work was partially supported by the Italian Ministry of Health with Ricerca Corrente and 5x1000 funds.

\section{Footnote}

Provenance and Peer Review: This article was commissioned 
by the Guest Editors (Roberto Gasparri and Giulia Sedda) for the series "A New Era in Lung Cancer Care: from Early Diagnosis to Personalized Treatment" published in Shanghai Chest. The article has undergone external peer review.

Reporting Checklist: The authors have completed the CARE reporting checklist. Available at http://dx.doi.org/10.21037/ shc.2020.04.03

Conflicts of Interest: All authors have completed the ICMJE uniform disclosure form (available at http://dx.doi. org/10.21037/shc.2020.04.03). The series “A New Era in Lung Cancer Care: from Early Diagnosis to Personalized Treatment" was commissioned by the editorial office without any funding or sponsorship. The authors have no other conflicts of interest to declare.

Ethical Statement: The authors are accountable for all aspects of the work in ensuring that questions related to the accuracy or integrity of any part of the work are appropriately investigated and resolved. All procedures performed in studies involving human participants were in accordance with the ethical standards of the institutional and/or national research committee(s) and with the Helsinki Declaration (as revised in 2013). The patient has given their consent for the case reports to be published.

Open Access Statement: This is an Open Access article distributed in accordance with the Creative Commons Attribution-NonCommercial-NoDerivs 4.0 International License (CC BY-NC-ND 4.0), which permits the non-

doi: $10.21037 /$ shc. 2020.04 .03

Cite this article as: Lo Iacono G, Petrella F, Casiraghi M, Spaggiari L. One's learning is never complete: chronic highpressure life-treating pleural effusion in post-pneumonectomy patients. Shanghai Chest 2020;4:45. commercial replication and distribution of the article with the strict proviso that no changes or edits are made and the original work is properly cited (including links to both the formal publication through the relevant DOI and the license). See: https://creativecommons.org/licenses/by-nc-nd/4.0/.

\section{References}

1. Shen KR, Wain JC, Wright CD, et al. Postpneumonectomy syndrome: surgical management and long-term results. J Thorac Cardiovasc Surg 2008;135:1210-6; discussion 1216-9.

2. Adams HD, Junod F, Aberdeen E, et al. Severe airway obstruction caused by mediastinal displacement after right pneumonectomy in a child. A case report. J Thorac Cardiovasc Surg 1972;63:534-9.

3. Rodefeld MD, Wile FD, Whyte RI, et al. Pulmonary vascular compromise in a child with postpneumonectomy syndrome. J Thorac Cardiovasc Surg 2000;119:851-3.

4. Veronesi G, Spaggiari L, Solli PG, et al. Postpneumonectomy-like syndrome after chemoradiation therapy for lymphoma. Ann Oncol 2002;13:1945-7.

5. Abruzzini P. [Surgical treatment of fistulae of the main bronchus after pneumonectomy in tuberculosis (personal technic)]. Thoraxchirurgie 1963;10:259-64.

6. Petrella F, Spaggiari L, Post-Pneumonectomy Syndrome: an Old Challenge For New Technologies. J Thorac Cardiovasc Surg 2018;155:e139-40.

7. Stratakos G, Vitsas V, Koufos N, et al. Postpneumonectomy and post-lobectomy syndromes: case series and review of the literature. Monaldi Arch Chest Dis 2017;87:810. 